\title{
High performance novel gadolinium doped ceria/yttria stabilized zirconia/nickel layered and hybrid thin film anodes for application in solid oxide fuel cells
}

\author{
F.J. Garcia-Garcia ${ }^{\text {a }}$ *, A.M. Beltrán ${ }^{\text {b }}$, F. Yubero ${ }^{\text {a }}$, A.R. González-Elipe ${ }^{\text {a }}$, R.M. Lambert ${ }^{\text {a, c }}$ \\ a Laboratory of Nanotechnology on Surfaces, Instituto de Ciencia de Los Materiales de Sevilla (CSIC-Universidad de Sevilla), Avda, Américo Vespucio 49, 41092 Sevilla, Spain

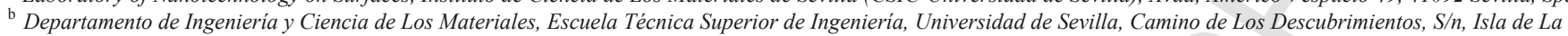 \\ Cartuja, 41092, Sevilla, Spain \\ ${ }^{c}$ Chemistry Department, Cambridge University, Cambridge CB2 1EW, United Kingdom
}

\section{A R T I C L E I N F O}

Article history:

Received 7 April 2017

Received in revised form 19 June 2017

Accepted 24 July 2017

Available online $\mathrm{xxx}$

Keywords:

Magnetron sputtering

Oblique angle deposition

Thin film anodes

Layered and hybrid structures

SOFC

\begin{abstract}
A B S T R A C T
Magnetron sputtering under oblique angle deposition was used to produce Ni-containing ultra thin film anodes comprising alternating layers of gadolinium doped ceria (GDC) and yttria stabilized zirconia (YSZ) of either $200 \mathrm{~nm}$ or $1000 \mathrm{~nm}$ thickness. The evolution of film structure from initial deposition, through calcination and final reduction was examined by XRD, SEM, TEM and TOF-SIMS. After subsequent fuel cell usage, the porous columnar architecture of the two-component layered thin film anodes was maintained and their resistance to delamination from the underlying YSZ electrolyte was superior to that of corresponding single component Ni-YSZ and Ni-GDC thin films. Moreover, the fuel cell performance of the 200 nm layered anodes compared favorably with conventional commercially available thick anodes. The observed dependence of fuel cell performance on individual layer thicknesses prompted study of equivalent but more easily fabricated hybrid anodes consisting of simultaneously deposited Ni-GDC and Ni-YSZ, which procedure resulted in exceptionally intimate mixing and interaction of the components. The hybrids exhibited very unusual and favorable I-V characteristics, along with exceptionally high power densities at high currents. Their discovery is the principal contribution of the present work.
\end{abstract}

(C) 2017 .

\section{Introduction}

Solid oxide fuel cells (SOFC) promise clean, efficient power generation on a large scale, although technical issues currently limit their widespread application [1]. The obstacles to be overcome are for the most part due to the high temperatures and thermal cycling encountered during operation, which lead to a variety of materials-related problems which limit device lifetime [2]. Among these, the integrity and durability of the anode/electrolyte interface is an important factor, even in the most commonly encountered case where the electrolyte is yttria stabilized zirconia (YSZ) and the anode is a Ni-YSZ cermet $[3,4]$. Instability due to mechanical stresses caused by differences in thermal expansion coefficients at key interfaces can result in cell failure [2-4]. We have shown that Ni-YSZ thin film anodes deposited on YSZ electrolyte by means of magnetron sputtering at oblique incidence yield thermally robust anode/electrolyte structures that resist delamination under temperature cycling and also provide good electrochemical performance under SOFC conditions [5-7]. The columnar anode architecture generated by this method provides excellent porosity and extensive triple-phase boundaries well suited to the intended application. Moreover, this microstructure in conjunction with the extreme thinness of the anodes (a few microns), allows

\footnotetext{
* Corresponding author.

Email address: fj.garcia@csic.es (F.J. Garcia-Garcia)
}

them to accommodate interfacial strain far better than the corresponding dense thin film cermets $[7,8]$.

It is known that incorporation of gadolinium doped ceria (GDC) into conventional thick film Ni-YSZ anodes interfaced with YSZ electrolyte improves SOFC performance when operated with hydrogen or with methane [9-13] although such modification increases the mismatch of thermal properties at the critically important GDC anode/YSZ electrolyte interface, which can result in poor adhesion and cracking of the anode during high temperature treatment [14]. Additionally, despite the favorable properties of $\mathrm{Ni}$ /ceria-based oxides in regard to direct electrochemical carbon conversion [15] the reactivity of ceria with YSZ during anode sintering has limited its use [16]. Recently, conventionally-prepared Ni-YSZ anodes infiltrated with Ce, Gd precursors, and then calcined, were found to deliver power densities much higher that the equivalent unmodified Ni-YSZ anodes [17].

We have previously shown [6,7] that anode nanostructure can favorably affect the performance of very thin film anodes of the type investigated here. In the present, our aim was to investigate the effect of systematically varying anode nano-scale structure by (i) changing the thickness of alternating layers in a composite anode and (ii) fully intermixing the components, in each case varying the number of three phase boundaries and hence, hopefully, anode performance. Accordingly we describe a new approach - the use of multilayer thin film anodes in which very thin layers of Ni-YSZ alternate with layers of Ni-GDC to provide good thermal matching at the anode/electrolyte interface and superior electrochemical performance under SOFC con- 
ditions compared to the corresponding single component Ni-YSZ and Ni-GDC thin film anodes produced by the same method and having the same micro-architecture.

To our knowledge, this is the first investigation of the structure, properties and performance of layered, two-component anode thin films. Most importantly, prompted by the observed strong dependence of fuel cell performance on the thickness of individual Ni-YSZ and Ni-GDC layers, hybrid Ni-YSZ-GDC anodes made by co-deposition of Ni-YSZ and Ni-GDC were investigated. In addition to being much more easily prepared than the layered anodes, the hybrids exhibited highly unusual and favorable I-V characteristics along with exceptionally high power densities at high currents, most likely due to the uniquely high degree of dispersion and intermixing of the constituent components. Their discovery is the principal contribution of the present work and the origin of their apparently unique behavior is discussed.

\section{Experimental: synthesis and characterization}

Ni-YSZ porous thin films were prepared by reactive pulsed DC magnetron sputtering using a power of $200 \mathrm{~W}, 80 \mathrm{kHz}$ frequency and a working pressure of $5 \times 10^{-3} \mathrm{mbar}$, while Ni-GDC porous thin films were prepared by reactive pulsed DC magnetron sputtering using a power of $160 \mathrm{~W}$ at $100 \mathrm{kHz}$ and a working pressure of $5 \times 10^{-3} \mathrm{mbar}$, using as plasma gas a mixture of $40 \mathrm{sccm} \mathrm{Ar}$ and $2.5 \mathrm{sccm} \mathrm{O}_{2}$. Two kinds of layered films were fabricated consisting of alternating layers of either $\sim 200 \mathrm{~nm} \mathrm{Ni} / \mathrm{YSZ}$ and $\sim 200 \mathrm{~nm} \mathrm{Ni} / \mathrm{GDC}$ or $\sim 1000 \mathrm{~nm} \mathrm{Ni} /$ YSZ and $\sim 1000 \mathrm{~nm} \mathrm{Ni/GDC}$, designated multi 200 and multi 1000 respectively. Hybrid Ni-YSZ-GDC thin films were prepared by co-deposition of Ni-YSZ (pulsed DC) and RF (GDC) sputtering using powers of $200 \mathrm{~W}$ (Ni-YSZ) and $150 \mathrm{~W}$ (GDC) respectively. In all cases the total film thickness was $4 \mu \mathrm{m}$. Before deposition, the chamber was maintained at a base pressure of $3 \times 10^{-6}$ mbar. Commercially available solid oxide half-cells comprising YSZ electrolyte and LSM cathode $(20 \mathrm{~mm}$ Single Electrode Cell - Cathode Only, FuelCellMaterials, USA) were used as substrates for electrochemical experiments performed with a commercial instrument (ProboStat, Norway). In the fuel cell experiments $100 \mathrm{sccm}$ of pure $\mathrm{H} 2$ were fed to the anode chamber with air supplied to the cathode chamber at $100 \mathrm{sccm}$. Pt mesh was used as the current collector for both anode and cathode. An electrochemical workstation (AUTOLAB, PGSTAT30) with a four-probe configuration was used to obtain current-voltage $(\mathrm{I}-\mathrm{V})$ and current-power $(\mathrm{I}-\mathrm{P})$ characteristics at $850^{\circ} \mathrm{C}$. SEM, XRD, TOF-SIMS, HAAD STEM, and XPS characterization were carried out on all the thin films investigated using a YSZ substrate.

Oblique angle deposition was carried out using three different targets: (i) a $50 \mathrm{~mm}$ diameter $\mathrm{Ni} / \mathrm{Zr} / \mathrm{Y}$ alloy $(68.8 / 26.6 / 4.6 \mathrm{wt} \%)$ of $99.9 \%$ purity, chosen to produce $\mathrm{YSZ}$ films containing $8 \mathrm{~mol} \% \mathrm{Y}_{2} \mathrm{O}_{3}$ and $50 \mathrm{vol} \% \mathrm{Ni}$. (ii) a $50 \mathrm{~mm}$ diameter Ni-GDC cermet $(31.2 /$ $68.8 \mathrm{wt} \%$ ) of $99.9 \%$ purity, chosen to produce GDC films containing $90 \% \mathrm{CeO}_{2}-10 \% \mathrm{Gd}_{2} \mathrm{O}_{3} \mathrm{~mol} \% \mathrm{Y}_{2} \mathrm{O}_{3}$ and 50 vol $\% \mathrm{Ni}$. (iii) for hybrid films, the aforementioned $\mathrm{Ni} / \mathrm{Zr} / \mathrm{Y}$ target was used in combination with a $50 \mathrm{~mm}$ diameter GDC target $(31.2 / 68.8 \mathrm{wt} \%)$ of $99.9 \%$ purity, the latter chosen to produce GDC film containing $90 \% \mathrm{CeO}_{2}$ - $10 \% \mathrm{Gd}_{2} \mathrm{O}_{3}$. The target-substrate distance was $5 \mathrm{~cm}$ with an angle of $80^{\circ}$ between target and substrate normal and the deposition rate was in the order of $2 \mu \mathrm{m} \mathrm{h}^{-1}$ in all cases. A more detailed description of the deposition procedure may be found elsewhere [5-7]. Oblique angle deposition resulted in formation of highly porous thin film anodes, crucial for achieving superior structural and electrical properties. The technique is very reproducible, straightforward, and well suited to scale-up, all sample preparations and analyses having been repeated at least twice $[8,18]$.

It is important to note that these films exhibited major differences in structure and porosity compared to dense non-porous films deposited at normal incidence angle, as previously described [6,7]. The small amount of available material and the opacity of our films precluded conventional BET and optical measurements of porosity, respectively. However we have previously shown [19-21] by optical measurements on different but similarly deposited transparent oxide films that oblique angle deposition produces $35-40 \%$ porosity. That achieved in the present case is likely to be very similar. Moreover, the post-deposition heat treatments that we employed further increased the porosity (as will be seen from a comparison of Figs. 1 and 2).

In the cases of the multi 200 and multi 1000 films, the first layer in contact with the YSZ electrolyte was deliberately chosen to be Ni-YSZ. We have already shown [6,7] that very thin Ni-YSZ porous anodes (also made by oblique incidence angle deposition) in contact with YSZ electrolyte are very resistant to delamination This is in strong contrast to dense anodes deposited at normal incidence, which undergo extensive delamination.

Film microstructures were examined by scanning electron microscopy (SEM) using a Hitachi S4800 field emission microscope and by scanning-transmission electron microscopy ((S)TEM) using a FEI Talos F200S microscope operated at an accelerating voltage of $200 \mathrm{kV}$ and equipped with Super-X energy dispersive X-ray spectrometry (EDX) system including two silicon drift detectors. Local compositional analysis of the samples were carried out by combining high-angle annular dark field imaging (HAADF) and EDX acquisition in STEM mode with spatial drift correction and a dwell time of $0.2 \mathrm{~s}$. TEM lamellas have been prepared by Focus Ion Beam (CITIUS, Universidad de Sevilla, Spain). X-ray diffraction (XRD) patterns were obtained using $\mathrm{Cu} \mathrm{K \alpha}$ radiation with a Panalytical X'Pert Pro diffractometer incorporating a diffracted beam graphite monochromator and 1D silicon strip detector ( $\mathrm{X}^{\prime}$ Celerator). They were recorded from $2 \theta 10^{\circ}-90^{\circ}$ with step size $0.026^{\circ}$ at $148 \mathrm{~s}$ per step. Analyses were performed using XPert HighScore Plus software. Time-of-flight secondary ion mass spectroscopy (ToF-SIMS) depth profiling analysis was performed on a TOF-SIMS type ION-TOF V instrument (Universidad de Extremadura, Spain) equipped with a Bipolyatomic primary ion source, a Cs/electron impact dual source column, and a low-energy electron flood gun for charge compensation of insulating samples.

\section{Results and discussion}

\subsection{Morphology and structure}

Three different types of film were synthesized and tested. Those designated multi 200 consisted of alternating layers of Ni-YSZ and Ni-GDC, each of $\sim 200 \mathrm{~nm}$ thickness. Similarly multi 1000 films comprised alternating layers of Ni-YSZ and Ni-GDC, each of $\sim 1000 \mathrm{~nm}$ thickness. In both cases, the first layer in contact with the YSZ electrolyte consisted of a Ni-YSZ cermet, whose presence provided excellent stability under thermal cycling. Hybrid films were made by co-deposition of Ni-YSZ and GDC as described above. In the as-deposited state, all three types of film exhibited the same characteristic highly porous columnar architecture, with well-defined boundaries between the Ni-YSZ and Ni-GDC layers (multi 200 and multi 1000) as seen in Fig. 1a-d. This microstructure is typical of thin films prepared by MS at oblique incidence angles [18].

Figure S1 shows the corresponding XRD data for the as-deposited films. All three films gave broad $\mathrm{NiO}$ peaks corresponding to small 

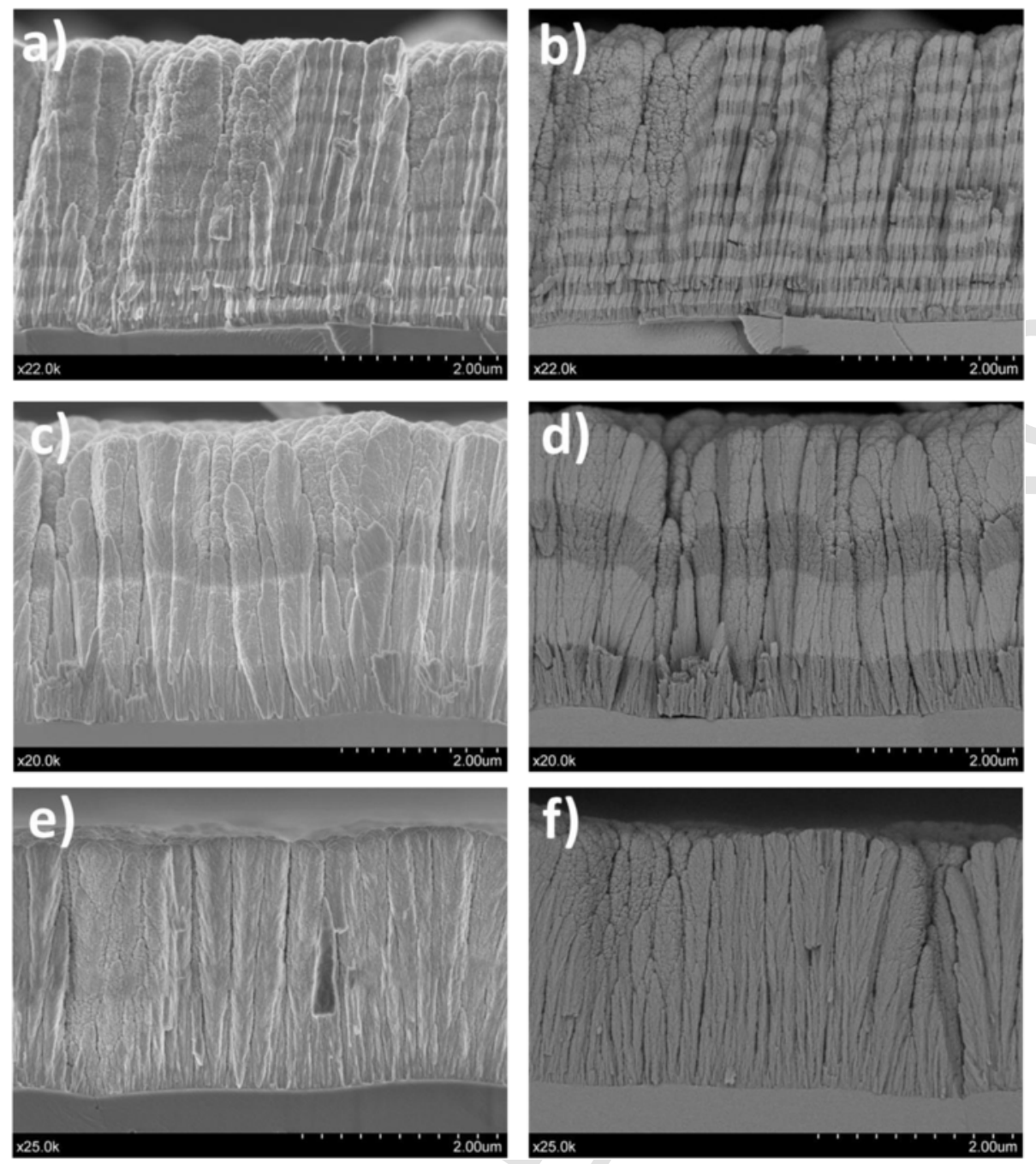

Fig. 1. SEM cross-section micrographs of the as deposited films (left secondary electrons; right backscattered electrons). (a) and (b) multi 200; (c) and (d) multi 1000; (e) and (f) hybrid.

nanometric aggregates whereas the GDC component was not visible: the intense YSZ peaks are due to the YSZ substrate [7].

The columnar structure was preserved after calcination, albeit with some lateral thickening, and the distinct layered structure of the multi 200 and multi 1000 films was also retained (Fig. 2a-f). In the latter case an interlayer of $\sim 130 \mathrm{~nm}$ was also clearly apparent at each YSZ/ GDC interface in the backscattered image as shown in Fig. $2 \mathrm{~d}$ and more clearly in the magnified image Fig. S2 in the supporting information. This interlayer is assigned to $\mathrm{NiO}$ because, as will be seen below, (i) after calcination the corresponding TOF-SIMS data reveal strongly increased $\mathrm{Ni}$ content at the interlayer and (ii) during subsequent reduction, HRTEM and TOF-SIMS show reduction of the interlayer to metallic Ni. The calcined hybrid film (Fig. 2e and f) did indeed exhibit a truly hybrid architecture. Pure YSZ films exhibit a pronounced granular structure [6] whereas pure GDC films show a characteristic "spongy" morphology [5]. In Fig. $2 \mathrm{f}$ it is apparent that the minority GDC component has eradicated the granularity of pure YSZ, yielding spongy columns.

During calcination, growth of crystalline $\mathrm{NiO}$ occurred in all three films, accompanied by crystallization of both YSZ [7] and GDC [5] in the multilayer films (see Fig. 3). However no detectable crystallization of GDC occurred in the hybrid film, implying a high degree of dispersion of this component. The degree of dispersion of the YSZ component cannot of course be assessed due to the strong contribution from the underlying YSZ electrolyte. Nevertheless, it seems reasonable to infer that the YSZ component on the hybrid anode was also highly dispersed. The new peaks just discernible at 34 and $50^{\circ}$ (magnified image in supporting information) do not correspond to $\mathrm{O}_{1.94} \mathrm{Y}_{0.12} \mathrm{Zr}_{0.88}$ - i.e. "normal" YSZ, but may be formally indexed to $\mathrm{O}_{1.862} \mathrm{Y}_{0.28} \mathrm{Zr}_{0.72}$ [22] a different cubic phase, which is also an ionic conductor. The implication is that some incorporation of $\mathrm{Ce}$ and $\mathrm{Gd}$ into the YSZ had occurred while the remaining GDC was dispersed as very small entities, invisible to XRD.

As shown in Fig. 4, the final reduction step produced highly porous thin films where both the YSZ and GDC interlayers and the hybrid material exhibited the same pronounced columnar architecture. Moreover, in Fig. 4d, which refers to a multi 1000 film, an interlayer was again clearly discernible between the YSZ and GDC layers: it is assigned to Ni metal, as confirmed below by TOF-SIMS and HAADF-STEM images. The formation of the nickel interlayer in the case of the multi 1000 film may be understood by the expulsion of $\mathrm{NiO}$ from the relatively thick YSZ and GDC layers during calcination. This effect does not occur with the thinner It is noteworthy that such interlayers do not appear in the case of the multi 200 films be- 

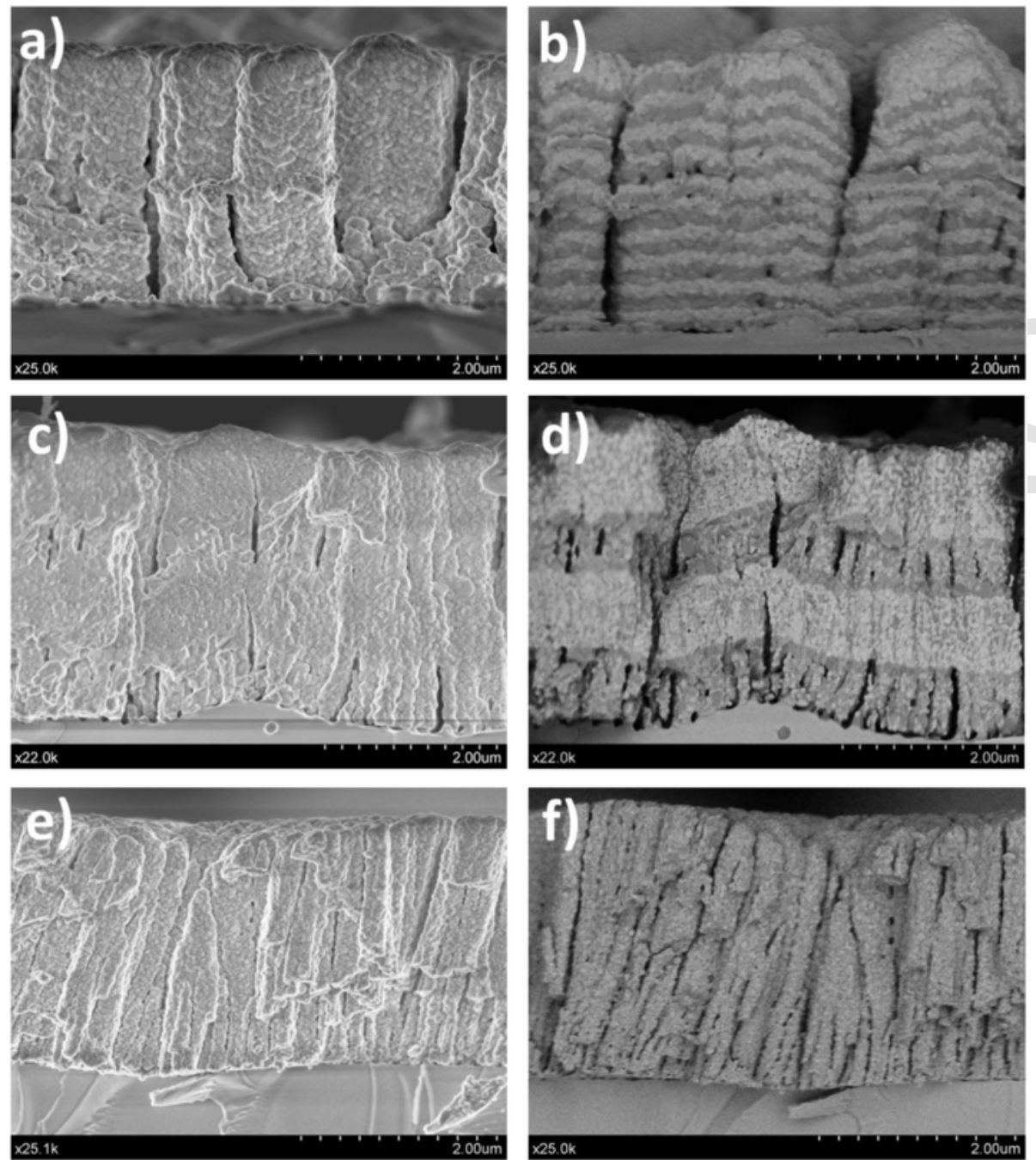

Fig. 2. SEM cross-section micrographs of calcined films (left secondary electrons; right backscattered). (Top) multi 200; (middle) multi 1000; (bottom) hybrid.
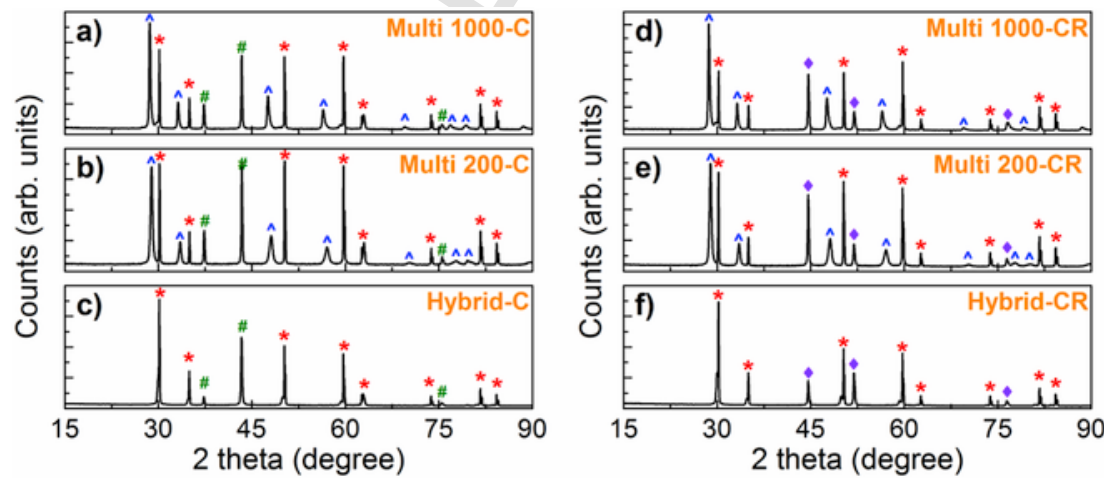

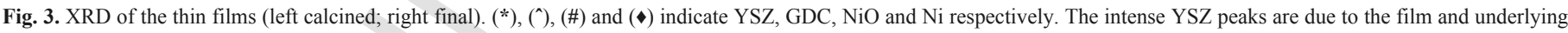
YSZ substrate.

cause the much thinner individual layers were able to accommodate their $5 \mathrm{x}$ lesser nickel oxide content. We may anticipate that the presence of the resulting Ni metal "barrier" layer in the reduced multi 1000 films could diminish their anodic performance relative to the other film types by (i) inhibiting their ability to transport oxide ions, (ii) decreasing the Ni content of the cermet phase and hence its cat- alytic activity and electronic conductivity and (iii) decreasing the extent of $\mathrm{Ni} /$ ceramic/gas three phase boundaries.

The XRD results (Fig. 3) confirmed that the final reduction step fully reduced $\mathrm{NiO}$ to $\mathrm{Ni}$ metal in all three types of film whose principal orientation was (111) in the case of the multilayer films, and (200) in the hybrid film. 

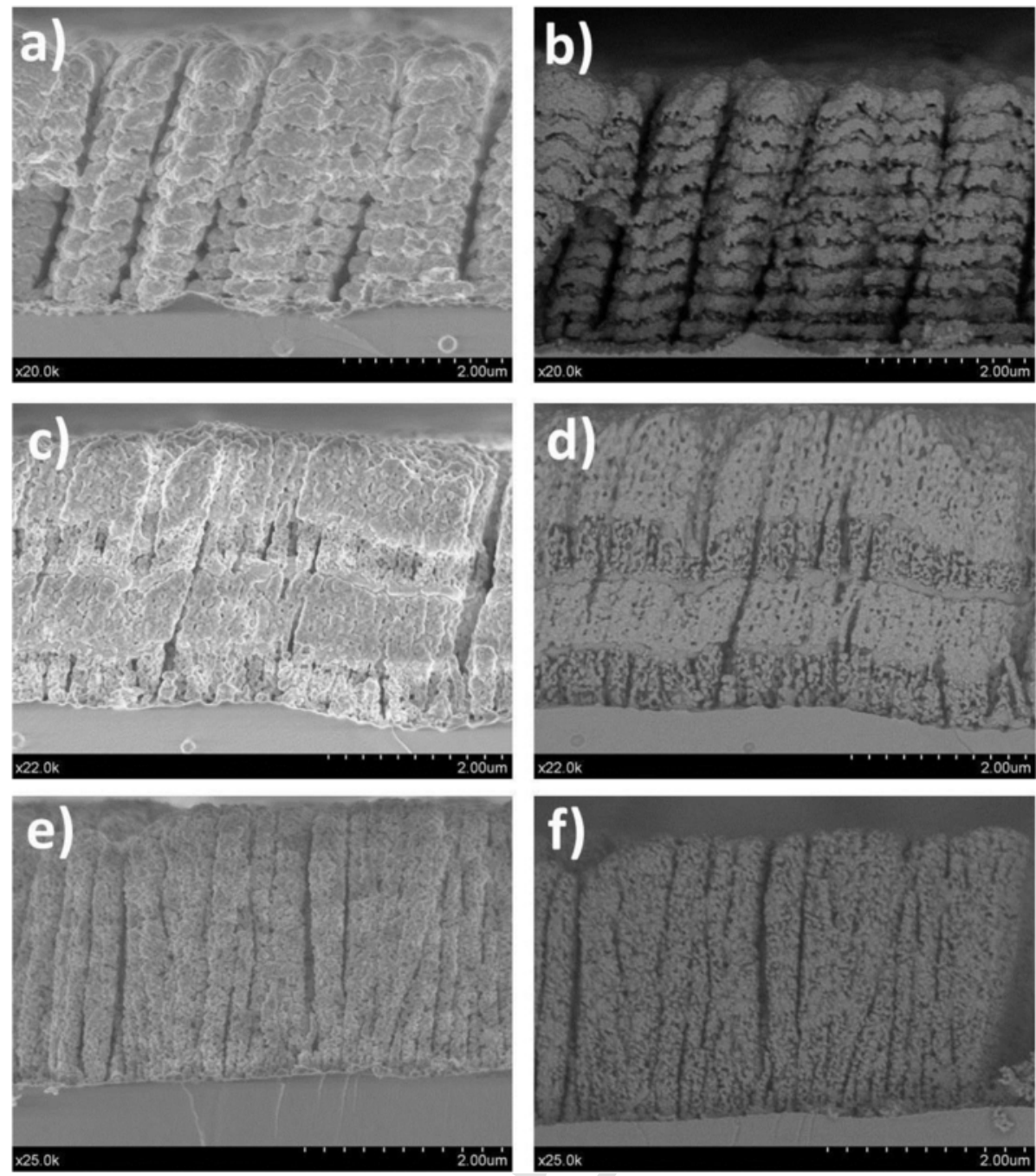

Fig. 4. SEM cross section micrograph of final reduced films (secondary electrons: left and backscattered: right). (Top) multi 200; (middle) multi 1000; (bottom) hybrid.

TOF-SIMS data were especially useful in providing information about the depth distribution of the five elements present. They are shown in the supporting information (figures S3-S5), are consistent with the three different morphologies observed by SEM, clearly show the well-defined interfaces, and provide unambiguous information about the distribution of elements throughout the films. Specifically, the as-deposited multilayer films are characterized by sharp interfaces (Figs. S4, S5) which underwent some "smoothing" after calcination and subsequent reduction (Figs. S7, S8 and Figs. S10, S11). This implies a degree of interdiffusion of the YSZ and GDC layers, as indeed confirmed below by HAADF-STEM.

Fig. 5 refers to a fully reduced hybrid anode, which is the most interesting case. It shows a HAADF-STEM image and the elemental maps taken from the area indicated in the HAADF image. Ni was present as $\sim 50 \mathrm{~nm}$ particles along with much smaller particles present on the ceramic phase. Relatively small amount of Gd coincides with the majority Ce component indicating that nanoscopic GDC had been formed, while the $\mathrm{Ce}$ and $\mathrm{Zr}$ maps show that these two ceramic phases were in intimate contact and surrounded the Ni particles. Overall, the indication is of a well-mixed material containing extensive three-phase boundaries and therefore well suited to the intended application.
Fig. 6 shows elemental maps taken from a multi 200 film at the YSZ/GDC boundary at the point indicated in the STEM image. It can be seen that substantial inter-diffusion of the two ceramic phases had taken place at the boundary between them, in good agreement with the TOF-SIMS data discussed above. In contrast, the nickel component was always distinctly separated from the other phases.

Fig. 7 shows corresponding information for the multi 1000 anode. Clearly apparent in this case is the presence of a well-developed $\sim 130 \mathrm{~nm}$ Ni interlayer between the GDC and YSZ phases, which most likely contributed to a reduction in electrochemical performance in the fuel cell tests to be described. Also apparent again is the inter-diffusion of the YSZ and GDC phases in the boundary region.

\subsection{Electrochemical performance of multilayer and hydrid anodes}

Fig. 8 shows representative $\mathrm{V}-\mathrm{I}$ (top) and $\mathrm{P}-\mathrm{I}$ (bottom) curves obtained with the three types of anodes using $\mathrm{H}_{2}$ as the fuel. Also shown for comparison are similar curves obtained under the same conditions with $\mathrm{Ni} / \mathrm{YSZ}$ and $\mathrm{Ni} / \mathrm{GDC}$ single anodes, as reported previously $[5,6]$. Strikingly, the performances of the two multilayer anodes that contained the same amount of $\mathrm{Ni}$ was very different - the multi 200 anode being far superior to the multi 1000 anode and also superior to the single component YSZ and GDC anodes. The inferior 

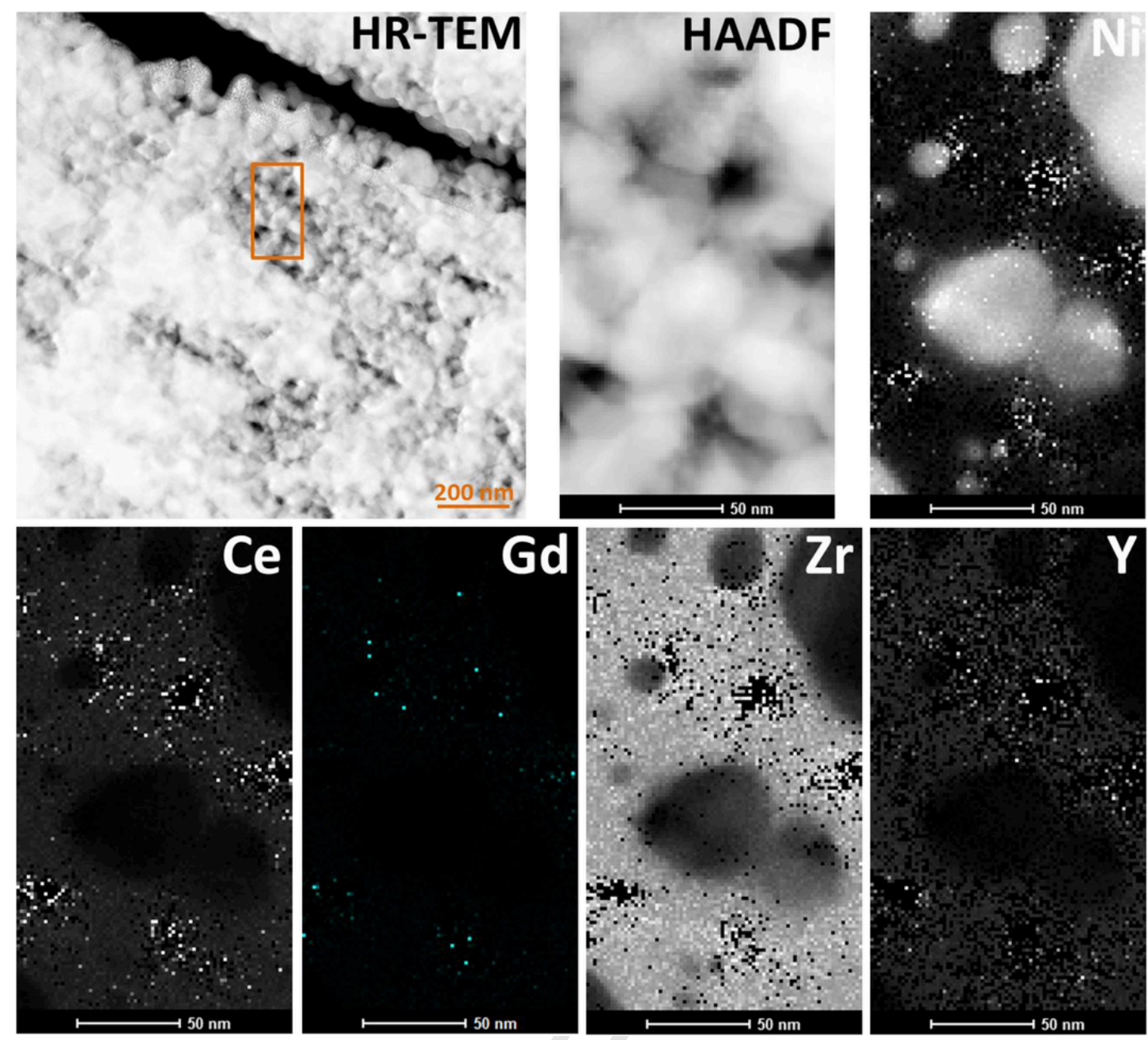

Fig. 5. Hybrid film. STEM images and elemental mappings for the final reduced anode.

performance of the multi 1000 anode is ascribed to the loss of integrity occurring at the interfaces between the two cermet phases as a result of $\mathrm{Ni}$ extrusion with formation of a metal barrier between them, as discussed above. Most significant of all, the much more easily synthesized hybrid anode approximated the behavior of the multi 200 anode, but also outperformed it, and the single component anodes, at current densities above $1 \mathrm{~A} \mathrm{~cm}^{-2}$. This material appears to represent a promising approach to the synthesis of thermally robust higher performance anodes. It contains GDC, which enhances electrocatalytic performance without incurring the disadvantage of anode/electrolyte delamination because the layer in contact with the YSZ electrolyte is itself YSZ-based. It is also much easier to fabricate than the thin multilayer structures, and, being based on magnetron sputtering, it is well suited to scale-up - unlike other approaches [17] to mixed anode fabrication, which in any case do not yield anything like such high performance materials as our hybrids.

What might be the source of the remarkable performance of the hybrid anode? The high dispersion of all components resulting from their simultaneous deposition presumably generated very extensive three phase boundaries, which should favor achieving high current densities. Additionally, the intimate interaction between the GDC and YSZ components may enhance electrochemical performance [17,23], via a mechanism that allows additional channels for ion transport to become available at high currents. Clearly, further investigation is de- sirable, including the effects of temperature, film thickness, Ni content and of varying the GDC/YSZ ratio. Impedance spectroscopy measurements could also shed further light on the origins of the behavior of the hybrid anode. This would require substantial additions work, beyond the scope of the present paper, involving fabrication of symmetrical cells with identical cathodes and anodes deposited at oblique incidence angle.

\section{Conclusions}

Thin film anodes consisting of alternating $200 \mathrm{~nm}$ layers of YSZ-Ni and GDC-Ni fabricated by oblique angle magnetron sputtering possess a porous micro-columnar architecture that resists delamination at the anode/electrolyte interface. With hydrogen as fuel, they performed substantially better than the corresponding single component anodes.

Similar multilayer anodes consisting of $1000 \mathrm{~nm}$ alternating ceramic layers performed relatively poorly due to formation of metallic $\mathrm{Ni}$ barrier interlayers at the GDC-Ni/YSC-Ni interfaces and associated changes in composition of the cermets.

Hybrid anodes synthesized by simultaneous deposition of Ni-GDC and Ni-YSZ showed very unusual and favorable I-V characteristics, along with retention of exceptionally high power densities at high currents. The exceptionally high degree of dispersion and inter- 

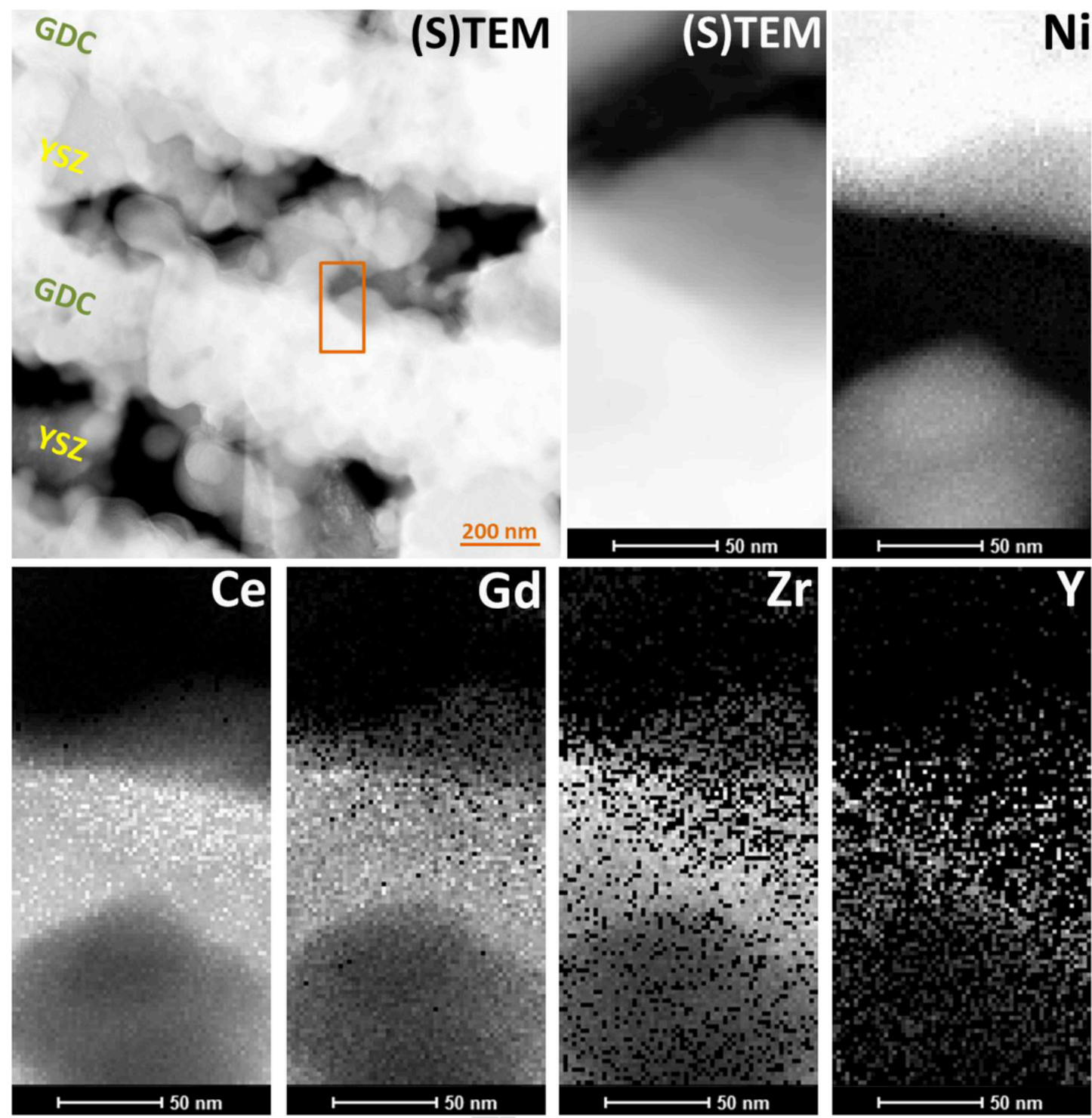

Fig. 6. Multi 200 film. HAADF-STEM images and elemental mappings for the final reduced anode

mixing of the anode components likely generates very extensive three phase boundaries and enhanced YSZ-GDC interaction. A mechanism that allowed additional channels for ion transport to become available at high currents may play a role in this behavior. Discovery of the hybrid anode is the principal contribution of the present work.

\section{Acknowledgements}

Support from the European Union's Seventh Framework Programme (FP7/2007-2013) for the Fuel Cells and Hydrogen Joint
Technology Initiative under the T-CELL project, grant 298300, and from MINECO (Spain), grants $n^{\circ}$ MAT2013-40852R and Juan de la Cierva Programme (FPDI-2013-18621) is also acknowledged.

\section{Appendix A. Supplementary data}

Supplementary data related to this article can be found at http://dx. doi.org/10.1016/j.jpowsour.2017.07.085 

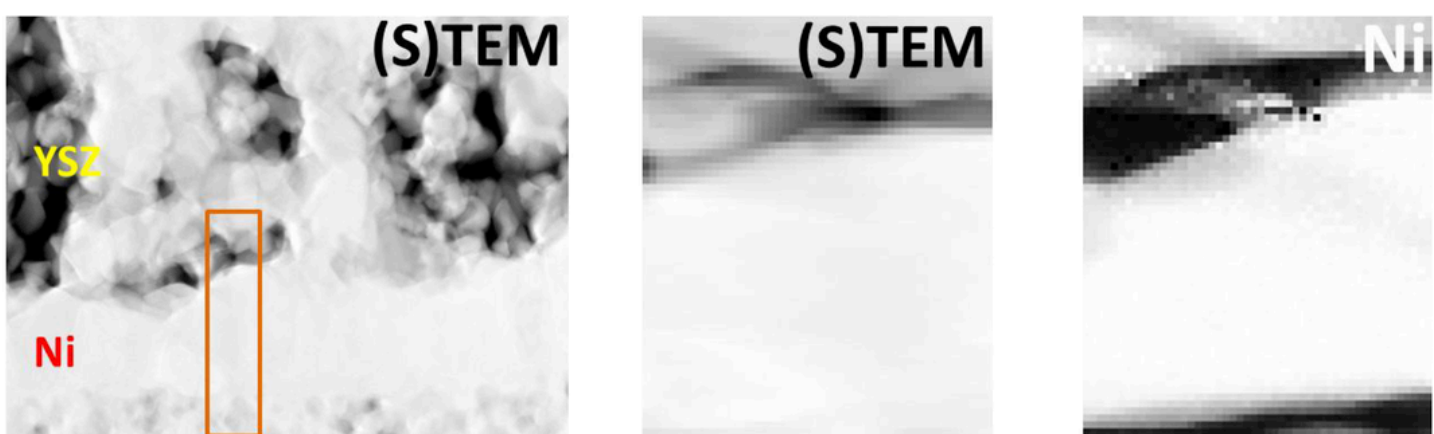

\section{GDC}
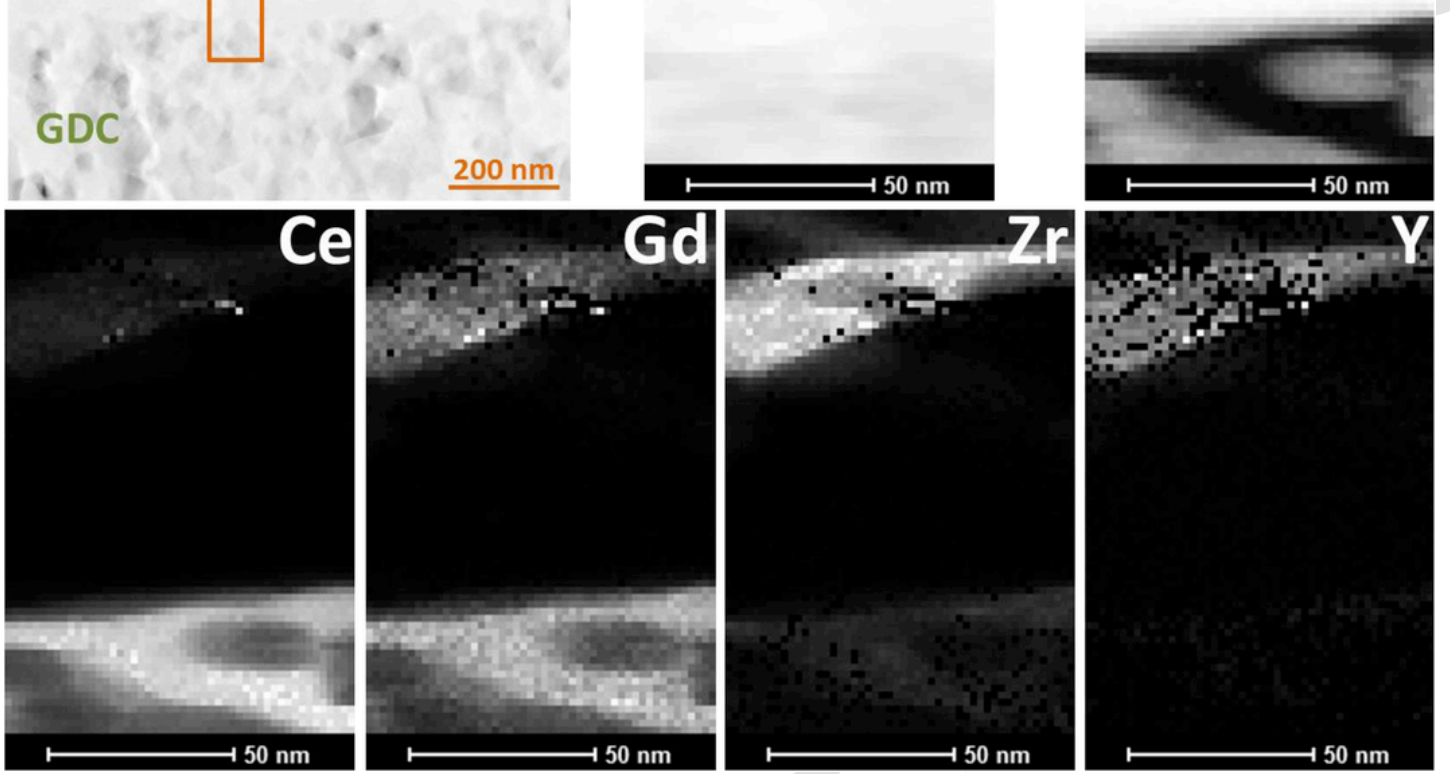

Fig. 7. Multi 1000 film. HAADF-STEM images and elemental mappings for the final reduced anode.

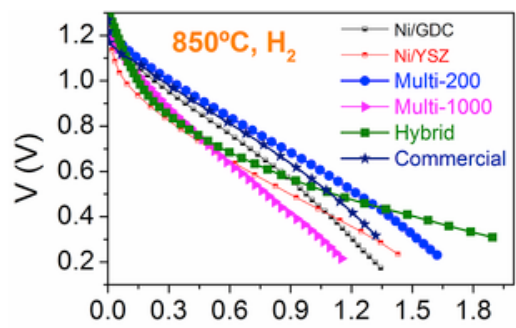

\section{References}

[1] W. Vielstich, A. Lamm, H.A. Gasteiger, Handbook of Fuel Cells: Fundamentals, Technology, and Applications, John Wiley and Sons, United Kingdom, 2003.

[2] N. Mahato, A. Banerjee, A. Gupta, S. Omar, K. Balani, Progress in material selection for solid oxide fuel cell technology: a review, Prog. Mat. Sci. 72 (2015) 141-337.

[3] A. Atkinson, S. Barnett, R.J. Gorte, J.T.S. Irvine, A.J. McEvoy, M. Mogensen, S.C. Singhal, J. Vohs, Advanced anodes for high-temperature fuel cells, Nat. Mater 3 (2004) 17-27.

[4] P.I. Cowin, C.T.G. Petit, R. Lan, J.T.S. Irvine, S. Tao, Recent progress in the development of anode materials for solid oxide fuel cells, Adv. Energy Mater 1 (2011) 314-332.

[5] F.J. Garcia-Garcia, F. Yubero, A.R. González-Elipe, R.M. Lambert, Microstructural engineering and use of efficient poison resistant Au-doped gadolinia-ceria ultrathin anodes in methane-fed solid oxide fuel cells, Int. J. Hydrogen Energy. (n.d.).

[6] F.J. Garcia-Garcia, F. Yubero, J.P. Espinós, A.R. González-Elipe, R.M. Lambert, Synthesis, characterization and performance of robust poison-resistant ultrathin film yttria stabilized zirconia - nickel anodes for application in solid electrolyte fuel cells, J. Power Sources 324 (2016) 679-686.

[7] F.J. Garcia-Garcia, F. Yubero, A.R. González-Elipe, S.P. Balomenou, D. Tsiplakides, I. Petrakopoulou, R.M. Lambert, Porous, robust highly conducting Ni-YSZ thin film anodes prepared by magnetron sputtering at oblique angles for application as anodes and buffer layers in solid oxide fuel cells, Int. J. Hydrogen Energy 40 (2015) 7382-7387.

Fig. 8. (Top) V-i and (bottom) P-i curves for all three types of anode obtained at $850^{\circ} \mathrm{C}$ with hydrogen as fuel. Single Ni/YSZ and Ni/GDC thin films and a commercial state-of-the-art SOFC (from fuelcellmaterials) are introduced for comparison. (Corresponding Ni/YSZ and Ni/GDC data reproduced with permission from Journal of Power Sources 324 (2016) 679 and Journal of Materials Chemistry A respectively).

[8] A.A. Solovyev, N.S. Sochugov, S.V. Rabotkin, A.V. Shipilova, I.V. Ionov, A.N. Kovalchuk, A.O. Borduleva, Application of PVD methods to solid oxide fuel cells, Appl. Surf. Sci. 310 (2014) 272-277.

[9] O. Costa-Nunes, R.J. Gorte, J.M. Vohs, Comparison of the performance of $\mathrm{Cu}-\mathrm{CeO} 2-\mathrm{YSZ}$ and Ni-YSZ composite SOFC anodes with $\mathrm{H} 2, \mathrm{CO}$, and syngas, J. Power Sources 141 (2005) 241-249.

[10]

J. Kong, K. Sun, D. Zhou, N. Zhang, J. Mu, J. Qiao, Ni-YSZ Gradient Anodes for Anode-supported SOFCs, 2007. 
[11]

J. Qiao, K. Sun, N. Zhang, B. Sun, J. Kong, D. Zhou, Ni/YSZ and Ni-CeO2/ YSZ Anodes Prepared by Impregnation for Solid Oxide Fuel Cells, 2007.

[12]

S.J. Kim, K.J. Kim, G.M. Choi, Effect of Ce0.43Zr0.43Gd0.1Y0.04O2- $\delta$ contact layer on stability of interface between GDC interlayer and YSZ electrolyte [13] in solid oxide electrolysis cell, J. Power Sources 284 (2015) 617-622.

X.-D. Zhou, B. Scarfino, H.U. Anderson, Electrical conductivity and stability of Gd-doped ceria/Y-doped zirconia ceramics and thin films, Solid State Ionics 175 (2004) 19-22.

$[14]$

E.P. Murray, T. Tsai, S.A. Barnett, A direct-methane fuel cell with a ceria-based anode, Nature 400 (1999) 649-651.

$[15]$

D.K. Niakolas, Sulfur poisoning of Ni-based anodes for solid oxide fuel cells in H/C-based fuels, Appl. Catal. A Gen. 486 (2014) 123-142.

$[16]$

A.C. Rady, S. Giddey, A. Kulkarni, S.P.S. Badwal, S. Bhattacharya, Direct carbon fuel cell operation on brown coal with a Ni-GDC-YSZ anode, Electrochim. Acta 178 (2015) 721-731.

[17]

R. Fernández-González, J.C. Ruiz-Morales, J. Canales-Vázquez, J.R. Jurado, A Makradi, P. Núñez, Decreasing the polarisation resistance of a Ni-YSZ solid oxide fuel cell anode by infiltration of a ceria-based solution, Int. J. Hydrogen Energy 41 (2016) 19731-19736.
$[18]$

A. Barranco, A. Borras, A.R. Gonzalez-Elipe, A. Palmero, Perspectives on oblique angle deposition of thin films: from fundamentals to devices, Prog. Mat. Sci. 76 (2016) 59-153.

[19]

F.J. Garcia-Garcia, J. Gil-Rostra, F. Yubero, A.R. Gonzalez-Elipe, Electrochromism in WOx and WxSiyOz thin films prepared by magnetron sputtering at glancing angles, Nanosci. Nanotechnol. Lett. 5 (2013) 89-93.

$[20]$

F.J. Garcia-Garcia, J. Gil-Rostra, A. Terriza, J.C. Gonzalez, J. Cotrino, F. Frutos, F.J. Ferrer, A.R. Gonzalez-Elipe, F. Yubero, Low refractive index SiOF thin

$[21]$ films prepared by reactive magnetron sputtering, Thin Solid Films 542 (2013).

J. Gil-Rostra, F.J. Garcia-Garcia, F. Yubero, A.R. Gonzalez-Elipe, Tuning the transmittance and the electrochromic behavior of CoxSiyOz thin films prepared by magnetron sputtering at glancing angle, Sol. Energy Mat. Sol. Cells 123 (2014) 130-138

[22]

Solid oxide fuel cells, in: R.H. Jeffrey, W. Fergus, Jiujun Zhang, Xianguo Li, David P. Wilkinson (Eds.), Materials Properties and Performance, CRC Press, Boca Raton, 2008.

[23]

S.P. Jiang, Nanoscale and nano-structured electrodes of solid oxide fuel cells by infiltration: advances and challenges, Int. J. Hydrogen Energy 37 (2012) $449-470$. 